\title{
Corticosteroid Therapy for Critically ill Patients with the Middle East Respiratory Syndrome
}

\author{
Yaseen M Arabi, MD, FCCP, FCCM (YA) \\ (ORCID: 0000-0001-5735-6241) \\ College of Medicine, King Saud Bin Abdulaziz University for Health Sciences, King Abdullah \\ International Medical Research Center, Riyadh, Saudi Arabia. \\ Intensive Care Department, King Abdulaziz Medical City, National Guard Health Affairs, \\ Riyadh, Saudi Arabia. \\ E-mail: arabi@ngha.med.sa \\ Yasser Mandourah, MD, FRCP(C), FCCP, ABIM (YM) \\ Department of Intensive Care Services, Prince Sultan Military Medical City, Riyadh, Saudi \\ Arabia. \\ Email: mandourah@hotmail.com
}

\section{Fahad Al-Hameed, MD, FRCPC (FH)}

Department of Intensive Care, King Saud bin Abdulaziz University for Health Sciences, King Abdullah International Medical Research Center, King Abdulaziz Medical City, Jeddah,

Saudi Arabia.

Email: $\underline{\text { Hameedf@ngha.med.sa }}$

\section{Anees A. Sindi, MBChB (AS)}

Department of Anesthesia and Critical Care, Faculty of Medicine, King Abdulaziz University, Jeddah, Saudi Arabia.

E-mail: ansindi@gmail.com

\section{Ghaleb. A. Al Mekhlafi, MD, SFCCM, EDIC(GM)}

Department of Intensive Care Services, Prince Sultan Military Medical City, Riyadh, Saudi

Arabia.

Email: gmekhlafi@yahoo.com

Mohamed A. Hussein, MSCS, MsPH, PhD. (MAH)

Department Biostatistics and Bioinformatics

King Saud Bin Abdulaziz University for Health Sciences, King Abdullah International Medical Research Center, Riyadh, Saudi Arabia.

E-mail: Husseinmo2@NGHA.MED.SA

Jesna Jose, MSc.Biostat (JJ)

Department Biostatistics and Bioinformatics

King Saud Bin Abdulaziz University for Health Sciences, King Abdullah International Medical Research Center, Riyadh, Saudi Arabia.

E-mail: joseje@ngha.med.sa

\section{Ruxandra Pinto, PhD Stat (RP)}

Sunnybrook Hospital

University of Toronto

Toronto, ON, Canada.

E-mail: Ruxandra.Pinto@sunnybrook.ca 
Awad Al-Omari, MD(AO)

College of Medicine, Alfaisal University, Riyadh, Saudi Arabia.

Department of Intensive Care, Dr Sulaiman Al-Habib Group Hospitals, Riyadh, Saudi Arabia.

E-mail: $\underline{\text { dr awad ksa@yahoo.com }}$

Ayman Kharaba, MD, FRCP(C) (AK)

Department of Critical Care, King Fahad Hospital, Ohoud Hospital, Al-Madinah Al-

Monawarah, Saudi Arabia.

a7yman@hotmail.com

Abdullah Almotairi, MBBS, FRCPC (AM)

Department of Critical Care Medicine, King Fahad Medical City, Riyadh, Saudi Arabia.

Email: aalmotairi@kfmc.med.sa

Kasim Al Khatib, MD, FCCP (KK)

Intensive Care Department, Al-Noor Specialist Hospital, Makkah, Saudi Arabia.

E-mail: kasimalkhatib@yahoo.com

Basem Alraddadi, MD, MSc (BR)

College of Medicine, Alfaisal University, Riyadh, Saudi Arabia.

Department of Medicine, King Faisal Specialist Hospital and Research Center, Jeddah, Saudi Arabia.

E-mail: basemalraddadi@gmail.com

Sarah Shalhoub, MD (SS)

Division of Infectious Diseases, Department of Medicine, King Fahad Armed Forces

Hospital, Jeddah, Saudi Arabia.

Email: sarah.shalhoub@googlemail.com

Ahmed Abdulmomen, MD (AA)

Department of Critical Care Medicine, King Saud University, Riyadh, Saudi Arabia.

E-mail: aturk@ksu.edu.sa

Ismael Qushmaq, MD, FRCPC, FACP (IQ)

Department of Medicine, King Faisal Specialist Hospital and Research Center, Jeddah,

Saudi Arabia.

Email: iqushmaq@kfshrc.edu.sa

Ahmed Mady, MD, FCCP, SFCCM

Intensive Care Department, King Saud Medical City, Riyadh, Saudi Arabia.

Tanta University Hospitals, Tanta, Egypt.

E-mail: afmady@hotmail.com

Othman Solaiman, MD (OS)

King Faisal Specialist Hospital and Research Center, Riyadh, Saudi Ara-bia.

E-mail: omsmd@yahoo.com

Abdulsalam M. Al-Aithan, MD (AA)

Intensive Care Department, King Abdulaziz Hospital, Al Ahsa, Saudi Arabia.

E-mail: AithanA@ngha.med.sa

Rajaa Al-Raddadi, MD, ABCM(RR)

Department of Research, Ministry of Health, Jeddah, Saudi Arabia.

E-mail: saudiresearcher@yahoo.com 
Ahmed Ragab, MD (AR)

Intensive Care Department, King Fahd Hospital, Jeddah, Saudi Arabia.

E-mail: ahmadragab63@hotmail.com

Hanan H Balkhy, MD, FAAP (HB)

College of Medicine, King Saud Bin Abdulaziz University for Health Sciences, King Abdullah International Medical Research Center, Riyadh, Saudi Arabia.

Department of Infection Prevention and Control, King Abdulaziz Medical City National Guard Health Affairs, Riyadh, Saudi Arabia.

E-mail: BalkhyH@ngha.med.sa

\title{
Abdulrahman Al Harthy, MD (AH)
}

Intensive Care Department, King Saud Medical City, Riyadh, Saudi Arabia.

E-mail: a almshal@hotmail.com

Ahmad M. Deeb, MSN, CCRC (AMD)

Research Office, King Saud Bin Abdulaziz University for Health Sciences, King Abdullah International Medical Research Center, Riyadh, Saudi Arabia.

E-mail: $\underline{\text { rn a deeb@hotmail.com }}$

Hanan Al Mutairi, BSDH, MHA. (HM)

Research Office, King Saud Bin Abdulaziz University for Health Sciences, King Abdullah International Medical Research Center, Riyadh, Saudi Arabia.

E-mail: almutairiha5@NGHA.MED.SA

\section{Abdulaziz Al-Dawood, MD, FRCPC, FCCP (AD)}

College of Medicine, King Saud Bin Abdulaziz University for Health Sciences, King Abdullah International Medical Research Center, Riyadh, Saudi Arabia.

Intensive Care Department, King Abdulaziz Medical City, National Guard Health Affairs, Riyadh, Saudi Arabia.

E-mail: aldawooda@hotmail.com

\section{Laura Merson (LM)}

International Severe Acute Respiratory and Emerging Infection Consortium (ISARIC), Infectious Diseases Data Observatory, Oxford University, Oxford, United Kingdom.

E-mail: laura.merson@ndm.ox.ac.uk

Frederick G. Hayden, M.D., F.A.C.P. (FGH)

International Severe Acute Respiratory and Emerging Infection Consortium (ISARIC), Division of Infectious Diseases and International Health, Department of Medicine, University of Virginia School of Medicine, Charlottesville, VA.

E-mail: $\underline{\text { FGH@hscmail.mcc.virginia.edu }}$

\author{
Robert A. Fowler, MDCM, MS (Epi), FRCP(C) (RAF) \\ Institute of Health Policy Management and Evaluation \\ University of Toronto \\ Department of Critical Care Medicine and Department of Medicine \\ Sunnybrook Hospital \\ Toronto, Canada 2075 Bayview Avenue, Room D478, \\ Email: rob.fowler@sunnybrook.ca \\ for the Saudi Critical Care Trial group
}


Corresponding Author

Yaseen M. Arabi, MD, FCCP, FCCM

Chairman, Intensive Care Department, MC 1425

Professor, College of Medicine

King Saud Bin Abdulaziz University for Health Sciences

King Abdullah International Medical Research Center

P.O. Box 22490 Riyadh 11426

Kingdom of Saudi Arabia

E-mail: Arabi@ngha.med.sa

Telephone: +966-11-8011111 x18899 / x18855 / x18877

Fax: +966-11-8011111 x18880 


\section{Author contributions}

YA: Conception and design, data acquisition, analytical plan, interpretation of data for the work, drafting of the manuscript, critical revision of the manuscript for important intellectual content, approval of the final version to be published and agreement to be accountable for all aspects of the work.

YM: Data acquisition, critical revision of the manuscript for important intellectual content, approval of the final version to be published and agreement to be accountable for all aspects of the work.

$\mathrm{FH}$ : Data acquisition, critical revision of the manuscript for important intellectual content, approval of the final version to be published and agreement to be accountable for all aspects of the work.

AS: Data acquisition, critical revision of the manuscript for important intellectual content, approval of the final version to be published and agreement to be accountable for all aspects of the work.

GM: Data acquisition, critical revision of the manuscript for important intellectual content, approval of the final version to be published and agreement to be accountable for all aspects of the work.

$\mathrm{MAH}$ : Conception and design, analytical plan, data analysis, critical revision of the manuscript for important intellectual content, approval of the final version to be published and agreement to be accountable for all aspects of the work.

$\mathrm{JJ}$ : Conception and design, analytical plan, data analysis, critical revision of the manuscript for important intellectual content, approval of the final version to be published and agreement to be accountable for all aspects of the work.

RP: Conception and design, analytical plan, critical revision of the manuscript for important intellectual content, approval of the final version to be published and agreement to be accountable for all aspects of the work.

AO: Data acquisition, critical revision of the manuscript for important intellectual content, approval of the final version to be published and agreement to be accountable for all aspects of the work.

AK: Data acquisition, critical revision of the manuscript for important intellectual content, approval of the final version to be published and agreement to be accountable for all aspects of the work.

AM: Data acquisition, critical revision of the manuscript for important intellectual content, approval of the final version to be published and agreement to be accountable for all aspects of the work.

KK: Data acquisition, critical revision of the manuscript for important intellectual content, approval of the final version to be published and agreement to be accountable for all aspects of the work.

BR: Data acquisition, critical revision of the manuscript for important intellectual content, approval of the final version to be published and agreement to be accountable for all aspects of the work. 
SS: Data acquisition, critical revision of the manuscript for important intellectual content, approval of the final version to be published and agreement to be accountable for all aspects of the work.

AA: Data acquisition, critical revision of the manuscript for important intellectual content, approval of the final version to be published and agreement to be accountable for all aspects of the work.

IQ: Data acquisition, critical revision of the manuscript for important intellectual content, approval of the final version to be published and agreement to be accountable for all aspects of the work.

AM.: Data acquisition, critical revision of the manuscript for important intellectual content, approval of the final version to be published and agreement to be accountable for all aspects of the work.

OS: Data acquisition, critical revision of the manuscript for important intellectual content, approval of the final version to be published and agreement to be accountable for all aspects of the work.

AA: Data acquisition, critical revision of the manuscript for important intellectual content, approval of the final version to be published and agreement to be accountable for all aspects of the work.

RR: Data acquisition, critical revision of the manuscript for important intellectual content, approval of the final version to be published and agreement to be accountable for all aspects of the work.

AR: Data acquisition, critical revision of the manuscript for important intellectual content, approval of the final version to be published and agreement to be accountable for all aspects of the work.

HB: Data acquisition, critical revision of the manuscript for important intellectual content, approval of the final version to be published and agreement to be accountable for all aspects of the work.

$\mathrm{AH}$ : Data acquisition, critical revision of the manuscript for important intellectual content, approval of the final version to be published and agreement to be accountable for all aspects of the work.

AMD: Conception and design, data acquisition, analytical plan, interpretation of data for the work, drafting of the manuscript, critical revision of the manuscript for important intellectual content, approval of the final version to be published and agreement to be accountable for all aspects of the work.

HM: Data acquisition, critical revision of the manuscript for important intellectual content, approval of the final version to be published and agreement to be accountable for all aspects of the work.

AD: Data acquisition, critical revision of the manuscript for important intellectual content, approval of the final version to be published and agreement to be accountable for all aspects of the work. 
LM: Conception and design, critical revision of the manuscript for important intellectual content, approval of the final version to be published and agreement to be accountable for all aspects of the work.

FGH: Conception and design, analytical plan, interpretation of data for the work, critical revision of the manuscript for important intellectual content, approval of the final version to be published and agreement to be accountable for all aspects of the work.

RAF: Conception and design, analytical plan, interpretation of data for the work, critical revision of the manuscript for important intellectual content, approval of the final version to be published and agreement to be accountable for all aspects of the work.

Funds and support: None

Running title: Corticosteroids for critically ill MERS patients

Descriptor number: 4.6 ICU Management/Outcome

The total word count for the body of the manuscript: 3859

The word count for the abstract: 244 


\section{At Glance Commentary}

\section{Scientific Knowledge on the Subject}

Corticosteroid therapy is commonly used among critically ill patients with the Middle East Respiratory Syndrome (MERS), but its impact on outcome is uncertain. Analyses of observational studies often do not account for time-varying confounders such as worsening clinical status, and the decision to prescribe corticosteroids, leading to potentially biased estimates of treatment effect.

\section{What This Study Adds to the Field}

This multicenter study investigated the association of corticosteroid therapy on mortality and MERS coronavirus RNA clearance accounting for time-varying confounders during critical illness, up-to the time of corticosteroid therapy initiation, using marginal structural models. Corticosteroid therapy in MERS patients was not associated with differences in mortality but was associated with delay in MERS coronavirus RNA clearance.

This article has an online data supplement, which is accessible from this issue's table of content online at www.atsjournals.org 


\begin{abstract}
Rationale: Corticosteroid therapy is commonly used among critically ill patients with the Middle East Respiratory Syndrome (MERS), but its impact on outcomes is uncertain. Analyses of observational studies often do not account for patients' clinical condition at the time of corticosteroid therapy initiation.
\end{abstract}

Objectives: To investigate the association of corticosteroid therapy on mortality and on MERS coronavirus RNA clearance in critically ill patients with MERS.

Methods: MERS ICU patients were included from 14 Saudi Arabian centers between September 2012 and October 2015. We carried out marginal structural modeling to account for baseline and time-varying confounders.

Measurements and Main Results: Of 309 patients, 151 received corticosteroids. Corticosteroids were initiated at a median of 3.0 days (Quartile Q1, 3: 1.0, 7.0) from ICU admission. Patients who received corticosteroids were more likely to receive invasive ventilation (141/151 [93.4\%] vs. 121/158 [76.6\%], $\mathrm{p} \leq 0.0001)$ and had higher 90-day crude mortality (112/151 [74.2\%] vs. 91/158 [57.6\%], p=0.002). Using marginal structural modeling, corticosteroid therapy was not significantly associated with 90 -day mortality (adjusted odds ratio $0.75,95 \% \mathrm{Cl} 0.52,1.07, \mathrm{p}=0.12$ ), but was associated with delay in MERS coronavirus RNA clearance (adjusted hazard ratio 0.35, 95\% Cl: 0.17, 0.72, $p=0.005)$.

Conclusions: Corticosteroid therapy in patients with MERS was not associated with a difference in mortality after adjustment for time-varying confounders, but was associated with delayed MERS coronavirus RNA clearance. These findings highlight the challenges and importance of adjusting for baseline and time-varying confounders when estimating clinical effects of treatments using observational 
studies.

Key words: Respiratory distress syndrome; coronavirus; coronavirus infections;

pneumonia; Saudi Arabia; corticosteroid. 


\section{Introduction}

Middle East Respiratory Syndrome coronavirus (MERS-CoV) is a pathogenic respiratory virus that often causes severe acute respiratory illness with substantial mortality. To date, there is no specific treatment for the MERS and management is largely supportive. $(1,2)$

Systemic corticosteroid therapy is commonly used among critically ill patients with MERS, but its impact on the clinical outcomes is uncertain.(3) Data from another related coronavirus infection, the Severe Acute Respiratory Syndrome (SARS) have been mainly observational and yielded inconsistent results. $(4,5)$ In a systematic review of studies on SARS, of 29 studies documenting corticosteroid use, 25 were inconclusive and four were classified as causing possible harm.(6) In one randomized controlled trial (RCT) that included 16 non-ICU patients, "early" ( $<7$ days of illness) hydrocortisone therapy was associated with a higher subsequent plasma viral load.(7) Similar controversy exists with severe influenza. A meta-analysis of multiple observational studies has shown that corticosteroid therapy was associated with increased mortality in patients with severe influenza.(8) Other serious adverse events including opportunistic infections, prolonged virus replication, and antiviral resistance emergence have also been observed.(9)

Challenging analytic issues with these studies include the risk of immortal time bias and indication bias from time-varying confounding.(10-13) Immortal time bias refers to the requirement for patients to survive long enough to receive the intervention of interest, leading to a potential incorrect estimation of a positive treatment effect.(13)(11) Indication bias from time-varying confounding refers to having an association related to the indication of the intervention that is evolving during the 
course of the illness. For example, a patient who becomes sicker has an inherent higher risk of death, but may also be more likely to receive $2^{\text {nd }}$ or $3^{\text {rd }}$ line therapies because $1^{\text {st }}$ line therapies have not led to improvement, possibly leading to an incorrect estimation of a negative treatment effect. Studies that adjust only for characteristics present at time of hospital or ICU admission do not account for the clinical condition at the time of corticosteroid therapy initiation, and thus do not account for potential emerging between-patient time-varying differences that can confound the relationship being investigated. Data from RCTs on corticosteroid therapy in MERS of sufficient size, that have a better chance of balancing such known and unknown confounders between groups receiving or not receiving corticosteroid therapy are lacking.

The objective of this study is to investigate the association of corticosteroid therapy on mortality and on MERS-CoV RNA clearance accounting for potential immortal time bias and indication bias. Some of this work has been previously presented in abstract form.(14)

\section{Methods}

\section{Setting}

We analyzed data from a multicenter, retrospective cohort study from 14 participating Saudi Arabian tertiary care hospitals.(3) The Institutional Review Boards of all participating centers approved the study. Patient-level informed consent was not required.

\section{Patients}


We included in this analysis all MERS patients admitted to the participating ICUs between September 2012 and October 2015. We excluded from the study patients known to be receiving chronic corticosteroid therapy prior to the onset of critical illness. Details of management and laboratory testing of MERS patients in the cohort have been reported previously.(3) For MERS-CoV positive patients, follow-up respiratory samples were collected at the discretion of the treating teams approximately 1-2 times per week to assess clearance of viral RNA for infection control purposes.

\section{Steroid therapy}

The main exposure was corticosteroid therapy defined as the use of systemic corticosteroids. We converted all preparations to hydrocortisone-equivalent doses (methylprednisolone 1:5, dexamethasone 1:25, prednisolone 1:4).

\section{Data collection}

Data were collected using standardized International Severe Acute Respiratory and Emerging Infection Consortium (ISARIC) case report forms.(15) We extracted data on patient demographic features, underlying co-morbidities, radiographic findings and the durations from symptom onset to presentation to the emergency department, ICU admission and intubation. We assessed severity of illness using the sequential organ failure assessment (SOFA) score, as well as laboratory and ventilator parameters on days 1, 3, 7, 14 and 28 of ICU admission. $(15,16)$ We collected data on the type, maximum daily dose and duration of corticosteroids, and we documented the use of antiviral therapy. 
The primary outcome was 90-day all-cause mortality. In patients who had at least one follow-up real-time reverse-transcription-polymerase-chain-reaction (rRT-PCR) performed after the diagnostic test, we examined the time to MERS-CoV RNA clearance in respiratory secretions by rRT-PCR defined as the time from ICU admission until the test was negative on 2 occasions, without a positive test afterwards. Secondary outcomes were ICU and hospital mortality, length of stay in the ICU and the hospital.

\section{Statistical analysis}

We compared baseline characteristics, co-interventions, and outcomes of patients who received corticosteroid therapy during ICU admission and those who did not receive any corticosteroid therapy using a Chi-square test or Fisher's exact test for categorical variables and Student's t-test or Mann-Whitney U test for continuous variables as appropriate. For serial measurements, we tested differences between the two groups over time using repeated measures analysis of variance with no imputation for missing values or correction for multiple comparisons.

\section{Association of corticosteroid therapy and 90-day mortality}

We tested the associations between corticosteroid therapy and mortality in three approaches: one approach that adjusts for baseline differences only, but does not account for immortal time bias or indication bias from time-varying confounding (logistic regression), a second approach that adjusts for baseline differences and accounts for immortal time bias but not indication bias from time-varying confounding (Cox proportional hazards regression accounting for time-varying exposure), and a 
third approach that adjusts for baseline differences and account for immortal time bias and indication bias from time-varying confounding (Marginal structural models).

\section{Logistic Regression}

To examine the independent association of corticosteroid therapy on 90-day mortality, we performed multivariable logistic regression analysis with corticosteroid therapy being the independent variable. We included in the multivariable model a priori decided baseline variables of clinical interest and all significant variables at the univariable level ( $p \leq 0.2$ ), which included: age, gender, day1 SOFA, asthma/chronic pulmonary disease, chronic cardiac disease, chronic neurological disease, diabetes with chronic complications, obesity, days from onset of symptom to ICU admission and health care worker status, by applying the PROC GENMOD procedure (SAS).

\section{Cox proportional hazards regression accounting for time-varying exposure}

To examine outcomes as a time-to-event (i.e. death), we carried out a Cox proportional hazard model adjusting for the same above-mentioned baseline covariates used with corticosteroid therapy as a time-varying covariate.

\section{Marginal structural model}

Because corticosteroid therapy often was not started at the time of ICU admission, but rather during the course of the disease based on a change in the patient condition, we carried out marginal structural model analysis with inverseprobability of treatment weighting to account for time-varying confounders that are likely to influence the corticosteroid therapy initiation and at the same time are likely to be correlated with the risk of mortality. $(10,17-19)$ We included the abovementioned baseline confounding variables as well. In this model we considered 
ventilation status and SOFA scores on the day of corticosteroid therapy initiation and the day before, as the time-varying variables. We reasoned that these variables capture the patient condition that physicians would most often consider when initiating corticosteroid therapy.

This process involves calculation of two weights for each observation: treatment selection weight and censoring weight. The treatment selection weight at time $\mathrm{k}$ is a ratio of two weights. The numerator is the product of probabilities that a patient receives his observed treatment at time $\mathrm{k}$, given the baseline covariates. The denominator is calculated similarly by incorporating also the time-varying covariates (SOFA on the day, SOFA on the previous day, mode of ventilation on the day and mode of ventilation on the previous day) as well. $(10,17)$ The weights are updated until the first day of corticosteroid therapy and kept constant afterwards. Because SOFA scores were recorded on days $1,3,7,14$ and 28 , we imputed missing values for the remaining days (Online Supplemental Methods). Ventilation status was recorded also on days $1,3,7,14$ and 28 , and we coded the mode of ventilation as follows: $0=$ no ventilation, $1=$ non-invasive ventilation, $2=$ invasive ventilation, $3=$ advanced ventilation support (e.g. ECMO, oscillatory, prone, nitric oxide). We imputed the mode of ventilation between these days by the Last-ObservationCarried-Forward method.

The same approach is used to calculate the censoring weight for early patient dropout. We have censored patients at hospital discharge or at day 90 and the weights for censoring are calculated as the ratio of a subject's probability of remaining uncensored up to day $\mathrm{k}$. The final weight for each observation is obtained by multiplying the treatment selection weights and the censoring weights. We used a 
weight-trimming approach to deal with extreme weights; weights larger than $95^{\text {th }}$ percentile value were fixed at the $95^{\text {th }}$ percentile value while the weights smaller than $5^{\text {th }}$ percentile value were fixed at the $5^{\text {th }}$ percentile value. This process continued until the average weight reached approximately 1 . The time-varying intercept was modeled by a smoothing function of time using restricted cubic splines with five knots for days since beginning of follow-up day $(17,19)$.

In step 2, weighted pooled logistic regression with robust standard error was used to estimate the effect of corticosteroids on mortality after adjusting for baseline characteristics. We modeled the probability of receiving corticosteroid therapy with the assumption that once the patient was started on corticosteroid therapy the patient will remain on that treatment.

\section{Association of corticosteroid therapy and MERS-CoV RNA clearance}

We tested the associations between corticosteroid therapy and MERS-CoV RNA clearance in two approaches: one approach that that adjusts for baseline differences and accounts for immortal time bias but not indication bias from time-varying confounding (Cox proportional hazards regression accounting for time-varying exposure), and a second approach that adjusts for baseline differences and accounts for both immortal time bias and indication bias from time-varying confounding (Marginal Structural Cox proportional hazards model).

\section{Cox proportional hazards regression accounting for time-varying exposure}

We used Cox proportional hazards regression to examine the time to MERSCoV RNA clearance rRT-PCR. For this analysis, we censored patients if they never cleared MERS-CoV RNA or at hospital discharge if they were discharged alive 
before they had cleared MERS-CoV RNA. We adjusted for the same baseline covariables used in the logistic regression model with corticosteroid therapy as a timevarying covariate.

\section{Marginal Structural Cox proportional hazards model}

Marginal Structural Cox proportional hazard model was carried out incorporating the stabilized weights to estimate the effect of corticosteroid therapy on MERS-CoV RNA clearance in a similar approach to the marginal structural model used for 90-day mortality above.

\section{Subgroup and sensitivity analyses}

Because a corticosteroid therapy effect may be dose-dependent and may vary according to the time of initiation, $(20,21)$ we carried out all previous models on the following stratified groups: patients who received high-dose corticosteroid therapy (highest daily dose of $>300 \mathrm{mg}$ of hydrocortisone-equivalent), patients who received low-dose corticosteroid therapy (highest daily dose of $\leq 300 \mathrm{mg}$ of hydrocortisone-equivalent), patients who had corticosteroid therapy initiated in the first 7 days of ICU admission, each compared to patients who did not receive any corticosteroid therapy. We also compared corticosteroid therapy started after day 7 compared to no corticosteroid therapy; in this analysis we only included patients who were alive after day 7 to ensure that patients in both groups were comparable in having "the opportunity" to receive the treatment thus minimizing the risk of confounding due to immortal time bias. To further assess the potential effect modification of the time of initiation of corticosteroid therapy on the association between corticosteroid therapy and 90-day mortality, we carried out landmark analyses at different time cutoff points by logistic regression analysis and Cox- 
proportional hazards model accounting for time-varying exposures. These analyses compared patients who were alive and with/without the exposure (corticosteroid/no corticosteroid) by each time cutoff point. To account for the possible variation by site, we carried out a sensitivity analysis using a logistic regression model adjusting for clustering by centers in addition to the previously mentioned baseline variables. To examine whether imputation of missing data had an impact on the association observed in the marginal structural model, and considering that corticosteroid therapy was initiated in $80 \%$ of patients in the first 7 days when imputation was relatively limited, we conducted a sensitivity analysis comparing patients who were started on corticosteroid therapy in the first 7 days with patients in the no corticosteroid therapy group with imputation up to day 7 only. To examine whether the results of the association of corticosteroid therapy and MERS-CoV RNA clearance might have been influenced by the practice of repeating rRT-PCR among different sites, we conducted a sensitivity analysis restricting to centers who had repeated $\mathrm{rRT}-\mathrm{PCR}$ on $>50 \%$ of their patients.

Tests were two-sided with significance set at $\alpha<0.05$. Results from all multivariable analyses are reported as odds ratios (OR) or hazard ratios (HR) with $95 \%$ confidence intervals (Cls) as appropriate. Analyses were conducted using SAS version 9.2 (SAS Institute, Cary, NC).

\section{Results}

\section{Patient characteristics}

Within the study period, 309 patients with MERS met the eligibility criteria for this study. Almost, half of these patients $151 / 309$ (48.9\%) received corticosteroid therapy. Patients receiving corticosteroid therapy and those not receiving 
corticosteroid therapy were similar in most baseline characteristics (Table 1).

However, patients given corticosteroid therapy were more likely to have one or more comorbidity than those without corticosteroid therapy $(132 / 151(87.4 \%)$ compared to $115 / 158(72.8 \%), p=0.001)$, including diabetes with chronic complications, chronic pulmonary disease and chronic cardiac disease (Table 1). The use of corticosteroid therapy varied by site (median percentage of patients on corticosteroid therapy $50 \%$, Q1, Q3: 34\%, 70\%, Figure E1)

\section{Corticosteroid use}

Hydrocortisone was the most frequently administered corticosteroid (103/151 [68.2\%] patients), followed by methylprednisolone (61/151 [40.4\%]) (Table 2). Corticosteroids therapy was started at a median of $3.0(1.0,7.0)$ from ICU admission. The median of the maximum daily hydrocortisone-equivalent dose was 300.0 (200.0, 400.0) $\mathrm{mg}$ with a median duration of $7.0(4.0,14.0)$ days. Figure 1 shows the distribution of the time to initiate corticosteroid therapy from ICU admission. Prior to corticosteroid therapy administration, the median $\mathrm{PaO}_{2} / \mathrm{FiO}_{2}$ was $108.8(68.8,166.2)$ $\mathrm{mmHg}$, and the median of positive end-expiratory pressure (PEEP) was 12.0 (10.0, 14.0) $\mathrm{cmH}_{2} \mathrm{O}$ (Table 2).

\section{Clinical Course and Outcomes}

Throughout their ICU stay, patients in the corticosteroid therapy group received more invasive ventilation, high-frequency oscillation ventilation, nitric oxide, neuromuscular blockers, vasopressors, blood transfusion, renal replacement therapy and received more ribavirin and interferon than patients who did not receive corticosteroid therapy (Table 3). Changes of physiological parameters over time and 
between the corticosteroid therapy group and no corticosteroid therapy group are described in Supplement Figure E2.

Patients who received corticosteroid therapy compared to those who did not had higher crude 90-day mortality (112/151 (74.2\%) compared to 91/158 (57.6\%), $p=0.0003)$, longer ICU length of stay $(12.5(8.0,23.0)$ days compared to 7.0 $(5.0,13.0)$ days, $p<0.0001)$ and hospital length of stay $(21.0(13.0,38.0)$ days compared to $15.0(8.0,30.0)$ days, $p=0.0006)$ (Table 3).

\section{Mortality}

After adjustment for baseline variables using multivariable logistic regression, corticosteroid therapy was associated with higher 90-day mortality (adjusted odds ratio $(a O R) 1.87,95 \% \mathrm{Cl} 1.02,3.44, p=0.045)$. Adjustment for clustering by site did not significantly alter this association (Supplemental Table 1). Using Cox proportional hazard analysis accounting for time-varying exposures, with adjustment for the same variables, corticosteroid therapy was not associated with mortality difference (adjusted hazard ratio (aHR) 1.20, 95\% Cl: 0.88, 1.63, p=0.24). Landmark analyses demonstrated that the associations observed with logistic regression and Cox proportional hazards analyses were time-dependent, with increasing aORs and aHRs when using increasing time cutoff points of initiation of corticosteroid therapy (Figure 2). Using marginal structural model, there were no significant association between corticosteroid therapy and 90-day mortality (aOR 0.75, 95\% Cl 0.52, 1.07, $p=0.12)$. Sensitivity analysis comparing patients who were started on corticosteroid therapy in the first 7 days to patients in the no corticosteroid therapy group and imputing missing data only up to day 7 did not alter the association $(n=260$, aOR 
$0.76,95 \% \mathrm{Cl} 0.50,1.15, \mathrm{p}=0.20)$. The dose and time of initiation of corticosteroid therapy were not associated with differences in 90-day mortality (Table 4).

\section{MERS-CoV RNA clearance}

Crude analyses showed no statistically significant differences in the proportion of patients who had MERS-CoV RNA clearance between the corticosteroid therapy group and the no corticosteroid therapy group, among all patients and among survivors (Table 3). Cox proportional hazards modeling accounting for time-varying exposure showed no significant association of corticosteroid therapy with the time to MERS-CoV RNA clearance (aHR 1.06, $95 \%$ Cl 0.61, 1.84; $p=0.84$, Table 4). However, using marginal structural Cox proportional hazards model, corticosteroid therapy was associated with a significant delay in MERS-CoV RNA clearance (aHR $0.35,95 \% \mathrm{Cl} 0.17,0.72 ; \mathrm{p}=0.005)$ (Table 4). Sensitivity analysis restricting to centers who had repeated $\mathrm{rRT}-\mathrm{PCR}$ on $>50 \%$ of their patients (11/14 centers, 168 patients) demonstrated a similar association (aHR 0.33, 95\% Cl 0.15, 0.72, p=0.005). A similar association with delayed MERS-CoV RNA clearance was observed when restricting analysis to low-dose, high-dose and early initiation of corticosteroid therapy. The association of late initiation of corticosteroid therapy (after 7 days) and MERS-CoV RNA clearance was not statistically significant (Table 4).

\section{Discussion}

Our study investigates the association of corticosteroid therapy on mortality and MERS-CoV RNA clearance accounting for time-varying confounders during critical illness. Our study shows that corticosteroid therapy in MERS patients was not 
associated with significant change in 90-day mortality after adjustment for timevarying confounders, but was associated with delayed MERS-CoV RNA clearance.

Our study shows that the corticosteroid therapy was commonly used for critically ill MERS patients. Corticosteroid therapy was initiated at variable times during the course of the disease. Patients were generally hypoxemic and on a moderate levels of PEEP at the time of starting therapy, indicating that corticosteroids were used for patients who quite ill and/or were not showing signs of improvement. Patients with comorbidities were more likely to receive corticosteroid therapy, as shown in other studies. $(10,22-24)$ The median daily dose in our study was in the range reported by others $(10,20)$, taking into consideration that we used the maximum daily dose in our analyses. The median time between the onset of critical illness and corticosteroid therapy was longer in our study than what has been reported in other respiratory infection case series,(10) which may reflect current recommendations to avoid corticosteroid therapy for MERS patients unless indicated for other reasons(25) and suggest that physicians used corticosteroids when the clinical condition was not improving.

Studies examining corticosteroid therapy and vital outcomes for patients with community-acquired pneumonia and ARDS have yielded conflicting results.(26-29) The results of studies on unselected patients with community-acquired pneumonia may not be generalizable to viral pneumonia - a viral etiology was documented in a small number of the included patients in these studies. Observational studies in patients with SARS coronavirus found that high-dose systemic corticosteroid therapy was associated not only with increased subsequent blood viral loads but also with adverse effects and increased mortality. $(5,7)$ 
RCTs are the best design to account for confounding factors. Multivariable analysis often uses baseline and not time-varying confounder adjustment, leading to residual confounding from immortal time bias and evolving indication bias from timevarying confounders. The landmark analyses in our study demonstrate the timedependent nature of associations. The use of time-varying confounding adjustment, including marginal structural models has been used fairly extensively in other fields that have longer periods of follow-up, such as studies on treatment of human immunodeficiency virus infection.(17) In critical care, observational studies have typically not considered time-varying confounding adjustment in shorter follow-up periods. However, such adjustment is particularly relevant when the likelihood of receiving a treatment and the likelihood of the outcome are both influenced by dynamic factors that change between baseline and the time at which treatment is received (in those who receive) and every time point at which the treatment might have been administered and wasn't (in those who don't receive). Our results are in accordance with the results derived from an observational study on influenza A (H1N1) in critically ill patients that showed no association between corticosteroid therapy and mortality when accounting for time-varying confounders using marginal structural model.(10) Our study demonstrates that measures of the association of corticosteroid therapy and mortality are critically dependent upon the analytic model chosen and highlights the need for RCTs as the most accurate way to obtain an estimate of the treatment effect. However, as cases of MERS are relatively infrequent and sporadic analyses of observational data may ultimate provide the best available evidence.

Our results reveal that corticosteroid therapy delayed the MERS-CoV RNA clearance. Similarly, corticosteroid therapy delayed the viral clearance in avian 
influenza $\mathrm{A}(\mathrm{H} 7 \mathrm{~N} 9)(20)$ and SARS.(7) This may be related to immune-suppressing effects of corticosteroid therapy, which are mediated mainly by T-cell responses(7). However, it is important to note that persistent positivity of MERS-CoV RNA does not necessarily indicate persistent shedding of live virus.

Our study is the first study to address corticosteroid therapy in MERS and is derived from the largest collaborative multicenter observational database on critically ill MERS patients, using standardized and detailed data collection. The retrospective observational design is a main limitation of our study. We used statistical methods that consider measured baseline and time-varying confounders. However, these adjustments may not be fully account for measured confounders and would not account for indication bias that could occur in the presence of unmeasured confounding. Since follow-up MERS-CoV RNA testing was at the discretion of the treating team, it is possible that patients with persistent viral shedding trajectories were more likely to get repeat RNA testing. This could be a source of bias since only patients with repeat testing were included in the analysis. However, we do not think the decision to repeat testing was related to the decision to treat with corticosteroids. In addition, we carried out a sensitivity analysis restricting to centers that had repeated testing on $>50 \%$ of patients, and found that the association of corticosteroid therapy with MERS-CoV RNA remained the same. We did not assess other associated outcomes with corticosteroid therapy, such as opportunistic infections, hyperglycemia and neuromyopathy. Marginal structural models require the availability of time-varying data on each time point around when the intervention may be initiated (each day in our case). While we used multiple a priori selected data time points to adjust for potential changes in severity of illness, we do not have data for each day and we needed to use imputation for days with missing data, and it is 
possible that additional data points would lead to even more valid estimates. However, $80 \%$ of patients were started on corticosteroid therapy in the first 7 days when missing data were relatively limited; thus minimizing the impact of imputation. Furthermore, sensitivity analysis restricting to the first week showed no change in the estimate of treatment effect. Because of the retrospective observational nature of our study, repeat rRT-PCR testing was not protocolized and varied among centers.

However, sensitivity analysis restricting to centers with more frequent testing showed that associations of corticosteroid therapy and viral clearance were robust.

Importantly, our findings cannot necessarily generalize to patients with other types of viral pneumonia or more broadly, patients with ARDS.

\section{Conclusions}

Corticosteroid therapy was commonly used in critically ill MERS patients. After adjustment for baseline and time-varying confounders, the use of corticosteroid therapy was not associated 90-day mortality but was associated with delayed MERS-CoV RNA clearance. 


\section{References}

1. World Health Organization: Middle East respiratory syndrome coronavirus (MERS-CoV). 2017 [cited 2017 17/04/2017]. Available from: http://www.who.int/emergencies/mers-cov/en/.

2. Arabi YM, Balkhy HH, Hayden FG, Bouchama A, Luke T, Baillie JK, Al-Omari A, Hajeer AH, Senga M, Denison MR, Nguyen-Van-Tam JS, Shindo N, Bermingham A, Chappell JD, Van Kerkhove MD, Fowler RA. Middle East Respiratory Syndrome. The New England journal of medicine 2017; 376: 584-594.

3. Arabi YM, Al-Omari A, Mandourah Y, Al-Hameed F, Sindi AA, Alraddadi B, Shalhoub S, Almotairi A, Al Khatib K, Abdulmomen A, Qushmaq I, Mady A, Solaiman O, Al-Aithan AM, Al-Raddadi R, Ragab A, Al Mekhlafi GA, Al Harthy A, Kharaba A, Ahmadi MA, Sadat M, Mutairi HA, Qasim EA, Jose J, Nasim M, Al-Dawood A, Merson L, Fowler R, Hayden FG, Balkhy HH, Saudi Critical Care Trial G. Critically III Patients With the Middle East Respiratory Syndrome: A Multicenter Retrospective Cohort Study. Crit Care Med 2017.

4. Yam LY, Lau AC, Lai FY, Shung E, Chan J, Wong V, Hong Kong Hospital Authority SCG. Corticosteroid treatment of severe acute respiratory syndrome in Hong Kong. The Journal of infection 2007; 54: 28-39.

5. Auyeung TW, Lee JS, Lai WK, Choi CH, Lee HK, Lee JS, Li PC, Lok KH, Ng YY, Wong WM, Yeung YM. The use of corticosteroid as treatment in SARS was associated with adverse outcomes: a retrospective cohort study. J Infect 2005; 51: 98-102.

6. Stockman L, Bellamy R, Garner P. SARS: systematic review of treatment effects. PLoS Med 2006; 3: e343.

7. Lee N, Allen Chan KC, Hui DS, Ng EK, Wu A, Chiu RW, Wong VW, Chan PK, Wong KT, Wong E, Cockram CS, Tam JS, Sung JJ, Lo YM. Effects of early corticosteroid treatment on plasma SARS-associated Coronavirus RNA concentrations in adult patients. J Clin Virol 2004; 31: 304309.

8. Lee N, Leo YS, Cao B, Chan PK, Kyaw WM, Uyeki TM, Tam WW, Cheung CS, Yung IM, Li H, Gu L, Liu $Y$, Liu Z, Qu J, Hui DS. Neuraminidase inhibitors, superinfection and corticosteroids affect survival of influenza patients. Eur Respir J 2015; 45: 1642-1652.

9. Rodrigo C, Leonardi-Bee J, Nguyen-Van-Tam JS, Lim WS. Effect of corticosteroid therapy on influenza-related mortality: a systematic review and meta-analysis. The Journal of infectious diseases 2015; 212: 183-194.

10. Delaney JW, Pinto R, Long J, Lamontagne F, Adhikari NK, Kumar A, Marshall JC, Cook DJ, Jouvet P, Ferguson ND, Griesdale D, Burry LD, Burns KE, Hutchison J, Mehta S, Menon K, Fowler RA, Canadian Critical Care Trials Group HNC. The influence of corticosteroid treatment on the outcome of influenza A(H1N1pdm09)-related critical illness. Crit Care 2016; 20: 75.

11. Shintani AK, Girard TD, Eden SK, Arbogast PG, Moons KG, Ely EW. Immortal time bias in critical care research: application of time-varying Cox regression for observational cohort studies. Crit Care Med 2009; 37: 2939-2945.

12. Sjoding MW, Luo K, Miller MA, Iwashyna TJ. When do confounding by indication and inadequate risk adjustment bias critical care studies? A simulation study. Crit Care 2015; 19: 195.

13. Suissa S. Effectiveness of inhaled corticosteroids in chronic obstructive pulmonary disease: immortal time bias in observational studies. Am J Respir Crit Care Med 2003; 168: 49-53.

14. Arabi YM, Mandourah Y, Al-Hameed F, Al Omari A, Sindi A, Alraddadi B, Shalhoub S, Al Motairi A, Al Khatib K, Abdul Mommin A, Qushmaq IA, Mady A, Solaiman O, Al Aithan A, Balkhy HH, AlRaddadi R, Rajab A, Mekhlafi G, Al Harthy A, Kharaba A, Al-Jabbary A , Pinto R, Sadat M, Al Mutairi H, Al Qasim E, Jose J, Deeb AM, Merson L, Hayden FG, Fowler R, Aldawood AS. The Association Of Corticosteroid Therapy And The Outcome Of Critically III Patients With The Middle East Respiratory Syndrome. Am J Respir Crit Care Med 2017;195:A6868

15. The International Severe Acute Respiratory and Emerging Infection Consortium (ISARIC) https://isarictghnorg/ Last accessed March 25, 2016. 
16. Vincent JL, de Mendonca A, Cantraine F, Moreno R, Takala J, Suter PM, Sprung CL, Colardyn F, Blecher S. Use of the SOFA score to assess the incidence of organ dysfunction/failure in intensive care units: results of a multicenter, prospective study. Working group on "sepsisrelated problems" of the European Society of Intensive Care Medicine. Crit Care Med 1998; 26: 1793-1800.

17. Hernan MA, Brumback B, Robins JM. Marginal structural models to estimate the causal effect of zidovudine on the survival of HIV-positive men. Epidemiology 2000; 11: 561-570.

18. Faries DE, Kadziola ZA. Analysis of Longitudinal Observational Data Using Marginal Structural Models. Analysis of Observational Health Care Data Using SAS 2010:211.

19. Robins JM, Hernan MA, Brumback B. Marginal structural models and causal inference in epidemiology. Epidemiology 2000; 11: 550-560.

20. Cao B, Gao H, Zhou B, Deng X, Hu C, Deng C, Lu H, Li Y, Gan J, Liu J, Li H, Zhang Y, Yang Y, Fang Q, Shen Y, Gu Q, Zhou X, Zhao W, Pu Z, Chen L, Sun B, Liu X, Hamilton CD, Li L. Adjuvant Corticosteroid Treatment in Adults With Influenza A (H7N9) Viral Pneumonia. Crit Care Med 2016; 44: e318-328.

21. Rochwerg B, Oczkowski S, Siemieniuk RA, Menon K, Szczeklik W, English S, Agoritsas T, BelleyCote E, D'Aragon F, Alhazzani W, Duan E, Gossack-Keenan K, Sevransky J, Vandvik P, Venkatesh B, Guyatt G, Annane D. Corticosteroids in sepsis: an updated systematic review and meta-analysis (protocol). BMJ Open 2017; 7: e016847.

22. Kim SH, Hong SB, Yun SC, Choi WI, Ahn JJ, Lee YJ, Lee HB, Lim CM, Koh Y, Korean Society of Critical Care Medicine HNC. Corticosteroid treatment in critically ill patients with pandemic influenza A/H1N1 2009 infection: analytic strategy using propensity scores. Am J Respir Crit Care Med 2011; 183: 1207-1214.

23. Brun-Buisson C, Richard JC, Mercat A, Thiebaut AC, Brochard L, Group R-SAHNvR. Early corticosteroids in severe influenza $A / H 1 N 1$ pneumonia and acute respiratory distress syndrome. Am J Respir Crit Care Med 2011; 183: 1200-1206.

24. Martin-Loeches I, Lisboa T, Rhodes A, Moreno RP, Silva E, Sprung C, Chiche JD, Barahona D, Villabon M, Balasini C, Pearse RM, Matos R, Rello J, Contributors EHNR. Use of early corticosteroid therapy on ICU admission in patients affected by severe pandemic (H1N1)v influenza A infection. Intensive Care Med 2011; 37: 272-283.

25. The World Health Orgnization. Clinical management of severe acute respiratory infection when Middle East respiratory syndrome coronavirus (MERS-CoV) infection is suspected .

Interim guidance. Updated 2 July 2015. http://www.who.int/csr/disease/coronavirus infections/case-management-ipc/en/ Accessed Sept 6, 2017.

26. Torres A, Sibila O, Ferrer M, Polverino E, Menendez R, Mensa J, Gabarrus A, Sellares J, Restrepo MI, Anzueto A, Niederman MS, Agusti C. Effect of corticosteroids on treatment failure among hospitalized patients with severe community-acquired pneumonia and high inflammatory response: a randomized clinical trial. Jama 2015; 313: 677-686.

27. Blum CA, Nigro N, Briel M, Schuetz P, Ullmer E, Suter-Widmer I, Winzeler B, Bingisser R, Elsaesser $H$, Drozdov D, Arici B, Urwyler SA, Refardt J, Tarr P, Wirz S, Thomann R, Baumgartner C, Duplain H, Burki D, Zimmerli W, Rodondi N, Mueller B, Christ-Crain M. Adjunct prednisone therapy for patients with community-acquired pneumonia: a multicentre, double-blind, randomised, placebo-controlled trial. Lancet 2015; 385: 1511-1518.

28. Snijders D, Daniels JM, de Graaff CS, van der Werf TS, Boersma WG. Efficacy of corticosteroids in community-acquired pneumonia: a randomized double-blinded clinical trial. Am J Respir Crit Care Med 2010; 181: 975-982.

29. Ruan SY, Lin HH, Huang CT, Kuo PH, Wu HD, Yu CJ. Exploring the heterogeneity of effects of corticosteroids on acute respiratory distress syndrome: a systematic review and metaanalysis. Crit Care 2014; 18: R63. 


\section{Figure legend:}

Figure 1: Time-to-corticosteroid therapy initiation from ICU admission. Day 0 includes patients who were already on corticosteroid therapy when admitted to ICU. Date of initiation of corticosteroid therapy was missing in 3 patients.

Figure 2: Landmark analyses at different time cutoff points by logistic regression analysis and Cox-proportional hazards model accounting for time-varying exposure to compared patients who were alive and with/without the exposure (corticosteroid/no corticosteroid) by each time cutoff point. 
Table 1. Baseline characteristics and physiological parameters on day 1 of admission to ICU among MERS patients in the corticosteroid therapy and no corticosteroid therapy groups.

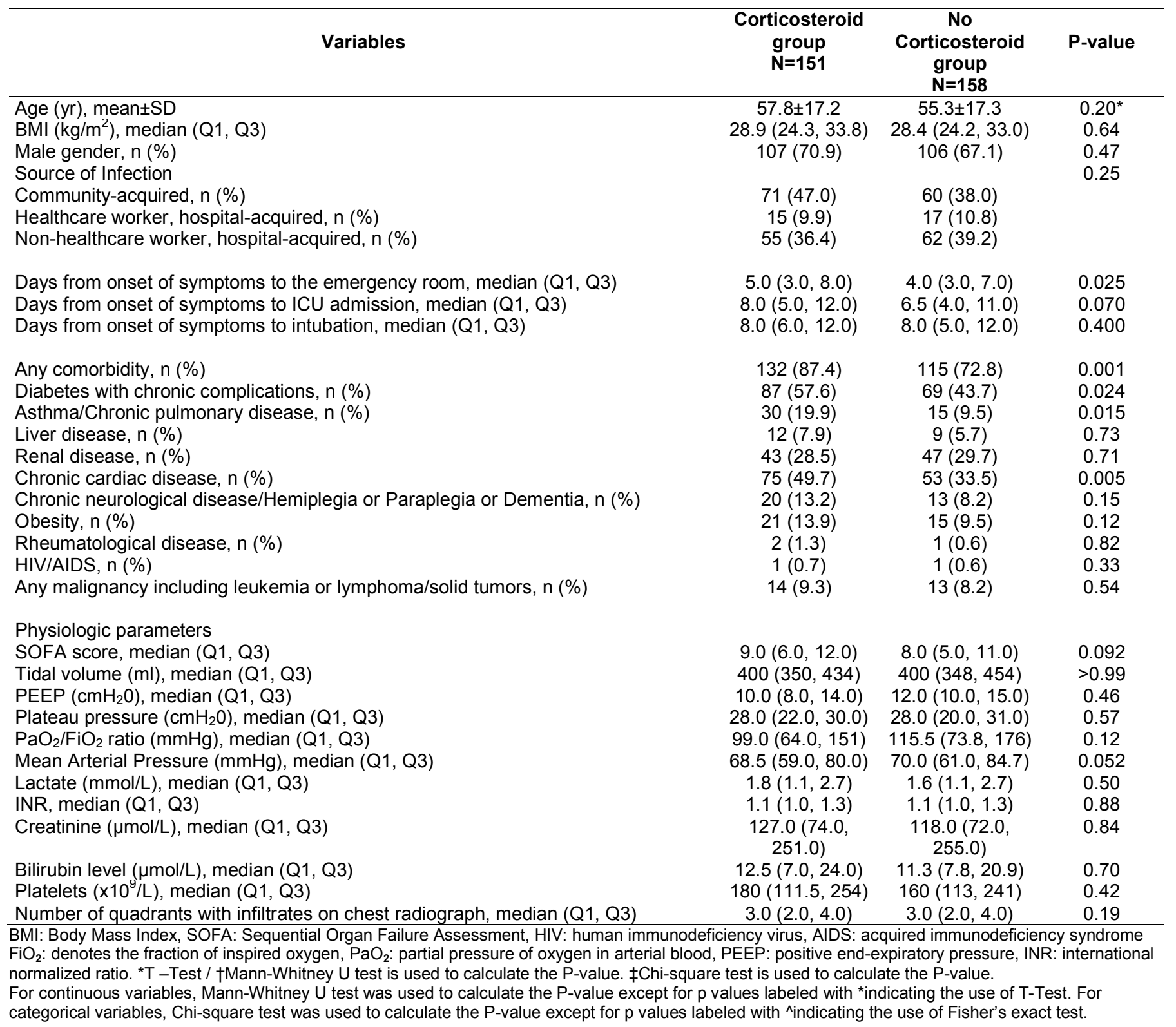


Table2. Corticosteroid therapy among critically ill patients with Middle East Respiratory Syndrome (MERS) $(n=151)$

\begin{tabular}{|c|c|}
\hline Medication Variable & Result \\
\hline Dexamethasone, $\mathrm{n}(\%)$ & $9 / 151(6.0)^{*}$ \\
\hline Hydrocortisone, n (\%) & $103 / 151(68.2)^{*}$ \\
\hline Methylprednisolone, $\mathrm{n}(\%)$ & $61 / 151(40.4)^{\star}$ \\
\hline Prednisolone, n (\%) & $20 / 151(13.2)^{*}$ \\
\hline \multicolumn{2}{|l|}{ Duration of corticosteroids, days, median (Q1, Q3) } \\
\hline All patients & $7.0(4.0,14.0)$ \\
\hline Survivors & $10.0(4.0,19.0)$ \\
\hline Non-survivors & $7.0(4.0,12.0)$ \\
\hline Dose, hydrocortisone equivalents per day (mg), median (Q1, Q3) & $300.0(200.0,400.0)$ \\
\hline Duration between onset of illness and corticosteroid initiation, days, median (Q1, Q3) & $10.0(7.0,17.0)$ \\
\hline Duration between hospital admission and corticosteroid initiation, days, median (Q1, Q3) & $7.0(3.0,15.0)$ \\
\hline Duration between ICU admission and corticosteroid initiation, days, median (Q1, Q3) & $3.0(1.0,7.0)$ \\
\hline Duration between onset of ventilation and corticosteroid initiation, days, median (Q1, Q3) & $3.0(1.0,7.0)$ \\
\hline $\mathrm{PaO}_{2} / \mathrm{FiO}_{2}$ prior to corticosteroid administration, median (Q1, Q3) & $108.8(68.8,166.2)$ \\
\hline Positive End Expiratory Pressure prior to corticosteroid administration $\left(\mathrm{cmH}_{2} \mathrm{O}\right)$, median $(\mathrm{Q} 1, \mathrm{Q} 3)$ & $12.0(10.0,14.0)$ \\
\hline SOFA Cardiovascular Score, prior to corticosteroid administration, median (Q1, Q3) & $1.0(0.0,3.0)$ \\
\hline
\end{tabular}

FiO2: denotes the fraction of inspired oxygen, $\mathrm{PaO} 2$ : partial pressure of oxygen in arterial blood, SOFA: Sequential Organ Failure Assessment

* Percentages add to more than $100 \%$ because some patients received more than one formulation of corticosteroids during ICU stay. 
Table 3. ICU course and outcomes among MERS patients in the corticosteroid therapy and no corticosteroid therapy groups.

\begin{tabular}{|c|c|c|c|}
\hline Variables & $\begin{array}{c}\text { Corticosteroids } \\
\mathrm{N}=151\end{array}$ & $\begin{array}{l}\text { No Corticosteroids } \\
\mathrm{N}=158\end{array}$ & P-value \\
\hline Invasive ventilation, $\mathrm{n}(\%)$ & $141(93.4)$ & $121(76.6)$ & $<0.0001$ \\
\hline High-frequency oscillation ventilation, $\mathrm{n}(\%)$ & $17(11.3)$ & $7(4.4)$ & 0.025 \\
\hline ECMO, n (\%) & $10(6.6)$ & $8(5.1)$ & 0.56 \\
\hline Nitric oxide, $\mathrm{n}(\%)$ & $29(19.2)$ & $10(6.3)$ & 0.0007 \\
\hline Prone positioning, $\mathrm{n}(\%)$ & $20(13.2)$ & $10(6.3)$ & 0.040 \\
\hline Ribavirin and/or interferon, $\mathrm{n}(\%)$ & $76(50.3)$ & $59(37.3)$ & 0.021 \\
\hline Ribavirin and interferon, $\mathrm{n}(\%)$ & $64(42.4)$ & $47(29.7)$ & \\
\hline Interferon only, $\mathrm{n}(\%)$ & $2(1.3)$ & $6(3.8)$ & $0.033^{\wedge}$ \\
\hline Ribavirin only, $\mathrm{n}(\%)$ & $10(6.6)$ & $6(3.8)$ & \\
\hline Oseltamivir, n (\%) & $89(58.9)$ & $80(50.6)$ & 0.14 \\
\hline Renal replacement therapy, n (\%) & $83(55.0)$ & $69(43.7)$ & 0.047 \\
\hline ICU length of stay, days, median (Q1, Q3) & $12.5(8.0,23.0)$ & $7.0(5.0,13.0)$ & $<0.0001$ \\
\hline Hospital length of stay, days, median (Q1, Q3) & $21.0(13.0,38.0)$ & $15.0(8.0,30.0)$ & 0.0006 \\
\hline MERS-CoV RNA clearance, n (\%) & $34 / 99(34.3)$ & $31 / 104(29.8)$ & 0.49 \\
\hline Time to MERS-CoV RNA clearance, days, median $(\mathrm{Q} 1, \mathrm{Q} 3)^{*}$ & $21.0(10.0,31.0)$ & $17.0(7.0,34.0)$ & 0.31 \\
\hline MERS-CoV RNA clearance among 90-day survivors, $n(\%)$ & $20 / 28(71.4)$ & $24 / 49(49.0)$ & 0.056 \\
\hline $\begin{array}{l}\text { Time to MERS-CoV RNA clearance among 90-day survivors, days, } \\
\text { median (Q1, Q3) }\end{array}$ & $23.0(11.0,32.5)$ & $17.5(9.5,36.5)$ & 0.62 \\
\hline \multicolumn{4}{|c|}{$\begin{array}{l}\text { ECMO: extracorporeal membrane oxygenation, ICU: Intensive care unit. For continuous variables, Mann-Whitney U test was used to calculate the P-value } \\
\text { For categorical variables, Chi-square test was used to calculate the P-value except for } p \text { values labeled with ^indicating the use of Fisher's exact test. } \\
{ }^{*} \text { Time to MERS-CoV RNA clearance was calculated for } 34 \text { patients in corticosteroid group and } 31 \text { patients in no-corticosteroid group. } \\
\text { **Time to MERS-CoV RNA clearance among } 90 \text {-day survivors was calculated for } 20 \text { patients in corticosteroid group and } 24 \text { patients in no-corticosteroid } \\
\text { group. }\end{array}$} \\
\hline
\end{tabular}




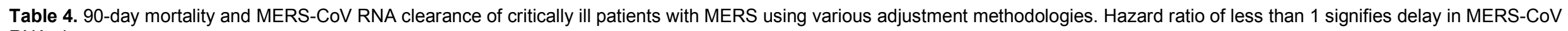
RNA clearance.

\begin{tabular}{|c|c|c|c|c|c|c|c|c|c|c|c|c|c|c|c|}
\hline \multicolumn{10}{|c|}{ Day-90 Mortality } & \multicolumn{6}{|c|}{$\begin{array}{c}\text { MERS-CoV RNA Clearance } \\
\end{array}$} \\
\hline \multirow[t]{2}{*}{ Variables } & \multicolumn{3}{|c|}{ Logistic regression } & \multicolumn{3}{|c|}{$\begin{array}{l}\text { Cox proportional hazard } \\
\text { model }\end{array}$} & \multicolumn{3}{|c|}{$\begin{array}{l}\text { Marginal structural model } \\
\text { (MSM) }\end{array}$} & \multicolumn{3}{|c|}{$\begin{array}{l}\text { Cox proportional hazard } \\
\text { model }\end{array}$} & \multicolumn{3}{|c|}{ Cox proportional MSM } \\
\hline & $\mathbf{n}$ & $\begin{array}{l}\text { aOR }(95 \% \\
\text { Cl) }\end{array}$ & $\begin{array}{c}\mathrm{p}- \\
\text { value }\end{array}$ & $\mathbf{n}$ & $\begin{array}{l}\text { aHR }(95 \% \\
\text { Cl) }\end{array}$ & $\begin{array}{c}\text { p- } \\
\text { value }\end{array}$ & $\mathbf{n}$ & $\begin{array}{l}\text { aOR }(95 \% \\
\mathrm{Cl})^{\#}\end{array}$ & $\begin{array}{c}\mathrm{p}- \\
\text { value }\end{array}$ & n & $\begin{array}{l}\text { aHR (95\% } \\
\text { Cl) }\end{array}$ & $\begin{array}{c}\text { p- } \\
\text { value }\end{array}$ & $\mathbf{n}$ & $\begin{array}{l}\text { aHR }(95 \% \\
\text { Cl) }\end{array}$ & $\begin{array}{c}\mathrm{p}- \\
\text { value }\end{array}$ \\
\hline $\begin{array}{l}\text { All patients treated with corticosteroids vs } \\
\text { patients not treated with corticosteroids (ref) }\end{array}$ & 291 & $\begin{array}{c}1.87 \\
(1.02,3.44)\end{array}$ & $\begin{array}{c}0.044 \\
5\end{array}$ & 291 & $\begin{array}{c}1.20 \\
(0.88,1.63)\end{array}$ & 0.24 & 290 & $\begin{array}{c}0.75 \\
(0.52,1.07)\end{array}$ & 0.12 & 194 & $\begin{array}{c}1.06 \\
(0.61,1.84)\end{array}$ & 0.84 & 189 & $\begin{array}{c}0.35 \\
(0.17,0.72)\end{array}$ & 0.005 \\
\hline $\begin{array}{l}\text { Patients treated with }>300 \mathrm{mg} \text { vs not treated } \\
\text { with corticosteroids (ref) }\end{array}$ & 185 & $\begin{array}{c}1.43 \\
(0.53,3.82)\end{array}$ & 0.48 & 185 & $\begin{array}{c}1.05 \\
(0.65,1.69)\end{array}$ & 0.84 & 184 & $\begin{array}{c}0.99 \\
(0.55,1.80)\end{array}$ & 0.98 & 121 & $\begin{array}{c}0.87 \\
(0.34,2.22)\end{array}$ & 0.78 & 118 & $\begin{array}{c}0.26 \\
(0.09,0.77)\end{array}$ & 0.015 \\
\hline $\begin{array}{l}\text { Patients treated with } \leq 300 \mathrm{mg} \text { vs not treated } \\
\text { with corticosteroids (ref) }\end{array}$ & 241 & $\begin{array}{c}1.89 \\
(0.94,3.82)\end{array}$ & 0.076 & 241 & $\begin{array}{c}1.21 \\
(0.86,1.71)\end{array}$ & 0.28 & 240 & $\begin{array}{c}0.75 \\
(0.51,1.11) \\
\end{array}$ & 0.15 & 164 & $\begin{array}{c}1.01 \\
(0.54,1.89)\end{array}$ & 0.98 & 159 & $\begin{array}{c}0.41 \\
(0.19,0.88)\end{array}$ & 0.022 \\
\hline $\begin{array}{l}\text { Patients treated for } \leq 7 \text { days vs not treated with } \\
\text { corticosteroids (ref) }\end{array}$ & 261 & $\begin{array}{c}1.81 \\
(0.91,3.59)\end{array}$ & 0.089 & 261 & $\begin{array}{c}1.05 \\
(0.76,1.46)\end{array}$ & 0.75 & 260 & $\begin{array}{c}0.88 \\
(0.61,1.26)\end{array}$ & 0.48 & 174 & $\begin{array}{c}0.59 \\
(0.31,1.13)\end{array}$ & 0.11 & 169 & $\begin{array}{c}0.23 \\
(0.09,0.63)\end{array}$ & 0.004 \\
\hline $\begin{array}{l}\text { Patients treated for }>7 \text { days vs not treated with } \\
\text { corticosteroids and who survived }>7 \text { days (ref) }\end{array}$ & 141 & $\begin{array}{c}2.49 \\
(0.85,7.25)\end{array}$ & 0.10 & 142 & $\begin{array}{c}1.60 \\
(0.88,2.89)\end{array}$ & 0.12 & 142 & $\begin{array}{c}0.51 \\
(0.26,1.00)\end{array}$ & 0.051 & 87 & $\begin{array}{c}3.12 \\
(1.31,7.40)\end{array}$ & 0.010 & 85 & $\begin{array}{c}0.94 \\
(0.36,2.47)\end{array}$ & 0.90 \\
\hline
\end{tabular}

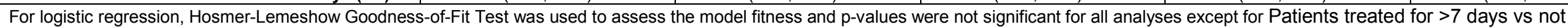
treated with corticosteroids and who survived> 7days" data. After removing an observation, which has the highest influence on the chi-square goodness-of-fit (based on residuals and deviance influence statistics), a non-significant p-value was obtained; we report the results after removing that point. 


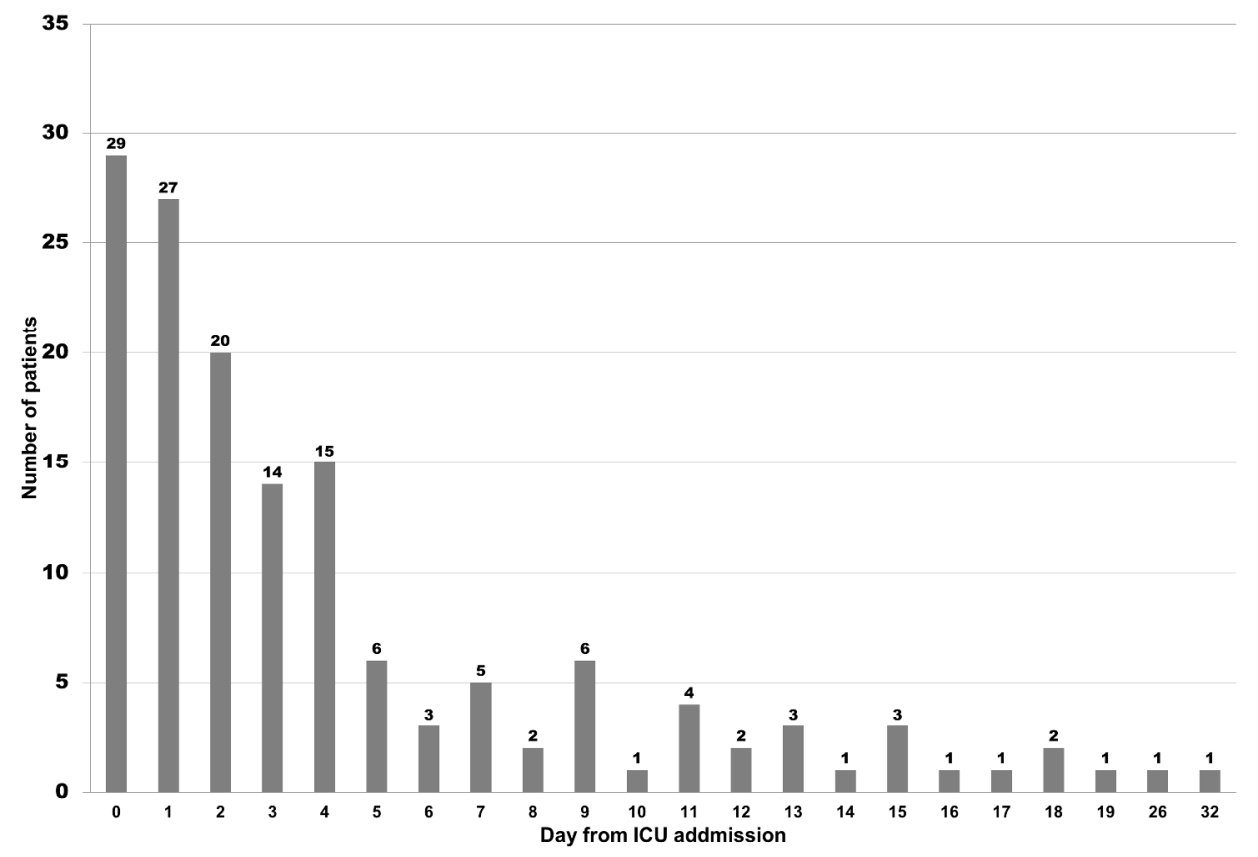

Figure 1: Time-to-corticosteroid therapy initiation from ICU admission. Day 0 includes patients who were already on corticosteroid therapy when admitted to ICU. Date of initiation of corticosteroid therapy was missing in 3 patients.

$1000 \times 800 \mathrm{~mm}(78 \times 78$ DPI $)$ 
Alive and exposure by

Day 3

Day 4

Day 6

Day 8

Day 10

Day 12

Day 14

\section{Corticosteroids No Corticosteroids \\ Events/N (\%) Events/N (\%) OR $(95 \% \mathrm{Cl})$ \\ 60/82 (73.2) $\quad 75 / 139 \quad(54.0)$ \\ $1.28(0.60,2.72)$}

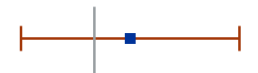

$P$ Value

0.52

$68 / 94 \quad(72.3) \quad 73 / 137 \quad(53.3) \quad 1.61(0.79,3.28)$

$66 / 93 \quad(71.0) \quad 51 / 115 \quad(44.3) \quad 1.83(0.89,3.77)$

$64 / 91 \quad(70.3) \quad 29 / 93 \quad(31.2) \quad 3.67(1.63,8.23)$

$54 / 82 \quad(65.9) \quad 23 / 87 \quad(26.4) \quad 4.48(1.90,10.56)$

$46 / 77 \quad(59.7)$

$17 / 81 \quad(21.0)$

$7.29(2.62,20.35)$

$42 / 72 \quad(58.3)$

$12 / 76 \quad(15.8)$

$10.1(3.35,30.27)$

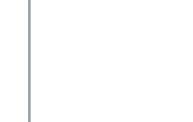

0.19

$>0.99$

0.002

0.001

$<0.001$

$<0.001$

Figure 2: Landmark analyses at different time cutoff points by logistic regression analysis and Cox-proportional hazards model accounting for time-varying exposure to compared patients who were alive and with/without the exposure (corticosteroid/no corticosteroid) by each time cutoff point. 
Alive and exposure by

Day 3

Corticosteroids No Corticosteroids

Events/N (\%) Events/N (\%) HR $(95 \% \mathrm{Cl})$

$60 / 82 \quad(73.2) \quad 75 / 139 \quad(54.0) \quad 0.88(0.61,1.28)$

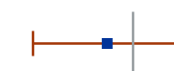

$P$ Value

0.52

Day 4

$68 / 94$

(72.3)

$73 / 137 \quad(53.3)$

$0.99(0.69,1.41)$

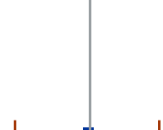

0.94

Day 6

$66 / 93$

(71.0)

$51 / 115 \quad$ (44.3)

$1.22(0.81,1.85)$

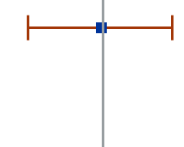

Day 8

$64 / 91$

(70.3)

$29 / 93$

(31.2)

$2.17(1.31,3.60)$

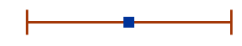

0.003

Day 10

$54 / 8$

(65.9)

$23 / 87 \quad(26.4)$

$2.50(1.42,4.40)$

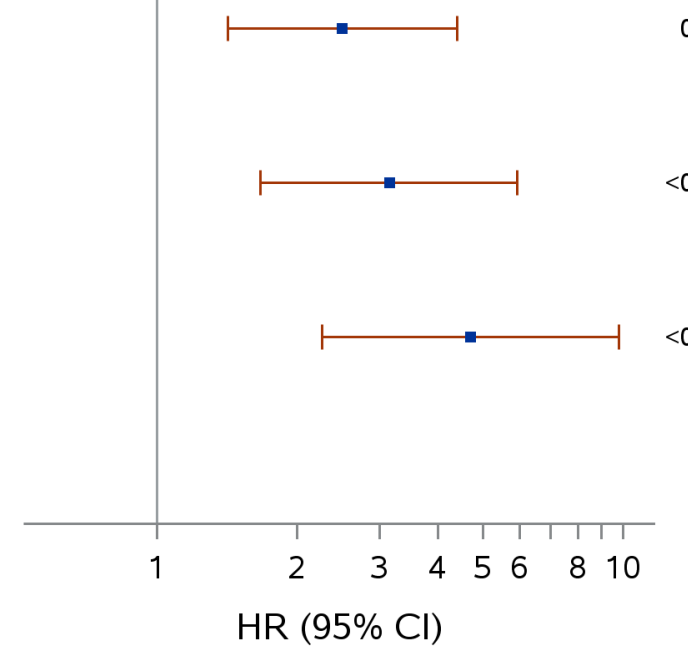

0.002

Day 12

$46 / 77 \quad(59.7)$

$17 / 81 \quad(21.0)$

$3.15(1.67,5.93)$

Day 14

$42 / 72 \quad(58.3)$

$12 / 76 \quad(15.8)$

$4.71(2.26,9.81)$

Figure 2 continued: Landmark analyses at different time cutoff points by logistic regression analysis and Cox-proportional hazards model accounting for time-varying exposure to compared patients who were alive and with/ without the exposure (corticosteroid/no corticosteroid) by each time cutoff point. 
Supplementary appendix to

Corticosteroid Therapy for Critically ill Patients with the Middle East Respiratory Syndrome

Yaseen Arabi; Yasser Mandourah; Fahad M Al-Hameed; Anees Sindi; Ghaleb A. Almekhlafi; Mohamed A. Hussein; Jesna Jose; Ruxandra Pinto; Awad Al-Omari; Ayman Kharaba; Abdullah AlMotairi; Kasim Al Khatib; Basem Alraddadi; Sarah Shalhoub; Ahmed Abdulmomen; Ismael Qushmaq; Ahmed Mady; Othman Solaiman; Abdulsalam M. Al-Aithan; Rajaa Al-Raddadi; Ahmed Ragab; Hanan H Balkhy, Abdulrahman Al Harthy; Ahmad M. Deeb; Hanan Al Mutairi; Abdulaziz Al-Dawood; Laura Merson; Frederick G. Hayden; Robert A. Fowler for the Saudi Critical Care Trial group. 


\section{Contents}

Collaborators

\section{Supplement to Methods}

\section{Supplement to Results}

Supplemental Table 1. Sensitivity analysis using logistic regression models with adjustment for clustering.

Supplement Figure E1. The use of corticosteiod therapy by site.

Supplement Figure E2. Physiological parameters in the corticosteroid therapy group and no corticosteroid therapy group. 


\section{Center}

Names

Saudi Arabia-The Saudi Critical Care Trial group

King Saud bin Abdulaziz University for Health Sciences and King Abdullah International Medical Research Center, Riyadh

King Fahad Medical City, Riyadh

Prince Sultan Cardiac Center, Riyadh

King Saud Medical City, Riyadh

King Faisal Specialist Hospital and Research Centre, Riyadh

King Khalid University hospital, Riyadh

Security Forces Hospital, Riyadh

King Abdulaziz Medical City, Jeddah

King Fahd Armed Forced Hospital, Jeddah

King Faisel Hospital Research Center, Jeddah

King Fahad Hospital Group, Jeddah

Yaseen Arabi

Abdulaziz Aldawood

Hanan Balkhy

Mohamed A. Hussein

Mashael Al Ahmadi

Musharaf Sadat

Hanan Al Mutairi

Eman Al Qasim

Ahmed Deeb

Hasan Aldorzi

Jesna Jose

Mundekkadan Shihab

Sheryl Ann Abdukahil

Aron Toledo

Lara Afesh

Mohammed Rafique Sohail

Abdullah Al Motairi

Ghaleb A. Almekhlafi

Yasser Mandourah

Sahar Hassan

Abid Alwan

Raylin Cabal

Rima E Mahamed

Khaloud M. Harbi

Abdulelah Ala Haidary

Abelrahman Al-Harthy

Ahmed Fouad Mady

Omar Elsayed Ramadan

Muhammed Asim Rana

Basim Raafat Huwait

Mohamed Ali Al-Odat

Waleed Tharwat Al-Atreeby

Othman Solaiman

Ahmed Abdul Mommin

Muhammed Fares

Mazen Barry

Awad Al Omari

Fahad Al-Hameed

Jalal AI Refai

Sarah Shalhoub

Basem M Alraddadi

Rashed E Alrehaili

Sarah Batawi

Anees Sindi

Rajaa Al-Raddadi

Ahmed Rajab

Omimah Shabouni

Abeer Mustafa Housa

Amal AbdulallaTurkistani

Abdullatif Ayesh Almarashi

Amaal Ali Sarraj 


Center

AINoor Specialist Hospital, Makkah

King Abdulaziz Medical city-Alahsa

King Fahad Hospital, Madinah

United Kingdom

Infectious Diseases Data Observatory, Oxford University

\section{Canada}

Sunnybrook Health Sciences Centre, Canada
Names

Salwa Awad Own

Sara Mohammed AlJeaid

Wijdan Abdulalkareem Baeshen

Kasim Al Khatib

Hamdy Badr

Majduldeen Azzo

Abdulsalam Alaithan

Ayman Kharaba

Noah Noor

Laura Merson

Robert Fowler

Ruxandra Pinto

United States of America

University of Virginia School of Medicine, USA
Frederick Hayden 


\section{Supplement to Methods}

Because SOFA scores were recorded on days 1, 3, 7, 14 and 28, we imputed missing values for the remaining days using the following rules:

1. If ICU LOS $\geq 28$, we used linear interpolation for each of the intervals 4 to 6 days, 8 to 13 days and 15 to 27 days.

2. If $14 \leq$ ICULOS $\leq 27$, we used linear interpolation for 4 to 6 days and 8 to 13 days and the Last-Observation-CarriedForward method from day 15 onwards.

3. Missing values are managed similarly for the other LOS ICU that was less than 14 days. 
Supplemental Table 1. Sensitivity analysis using logistic regression models with adjustment for clustering by site did not significantly alter the associations of corticosteroid therapy and 90-day mortality.

\begin{tabular}{|c|c|c|c|}
\hline \multicolumn{4}{|l|}{ Day-90 Mortality } \\
\hline \multirow[t]{2}{*}{ Variables } & \multicolumn{3}{|c|}{ Logistic regression } \\
\hline & $\mathbf{n}$ & aOR (95\% Cl) & p-value \\
\hline $\begin{array}{l}\text { All patients treated with corticosteroids vs patients not treated with } \\
\text { corticosteroids (ref) }\end{array}$ & 291 & $1.87(1.18,2.96)$ & 0.007 \\
\hline Patients treated with $>300 \mathrm{mg}$ vs not treated with corticosteroids (ref) & 185 & $1.43(0.51,3.99)$ & 0.50 \\
\hline Patients treated with $\leq 300 \mathrm{mg}$ vs not treated with corticosteroids (ref) & 241 & $1.89(1.00,3.57)$ & 0.050 \\
\hline Patients treated for $\leq 7$ days vs not treated with corticosteroids (ref) & 261 & $1.81(0.99,3.33)$ & 0.055 \\
\hline $\begin{array}{l}\text { Patients treated for }>7 \text { days vs not treated with corticosteroids and who } \\
\text { survived }>7 \text { days (ref) }\end{array}$ & 142 & $1.96(0.41,9.41)$ & 0.40 \\
\hline
\end{tabular}


Supplement Figure E1. The use of corticosteiod therapy by site. The use of corticosteroid therapy varied by site (median percentage of patients on corticosteroid therapy $50 \%$, Q1, Q3: $34,70 \%$ )

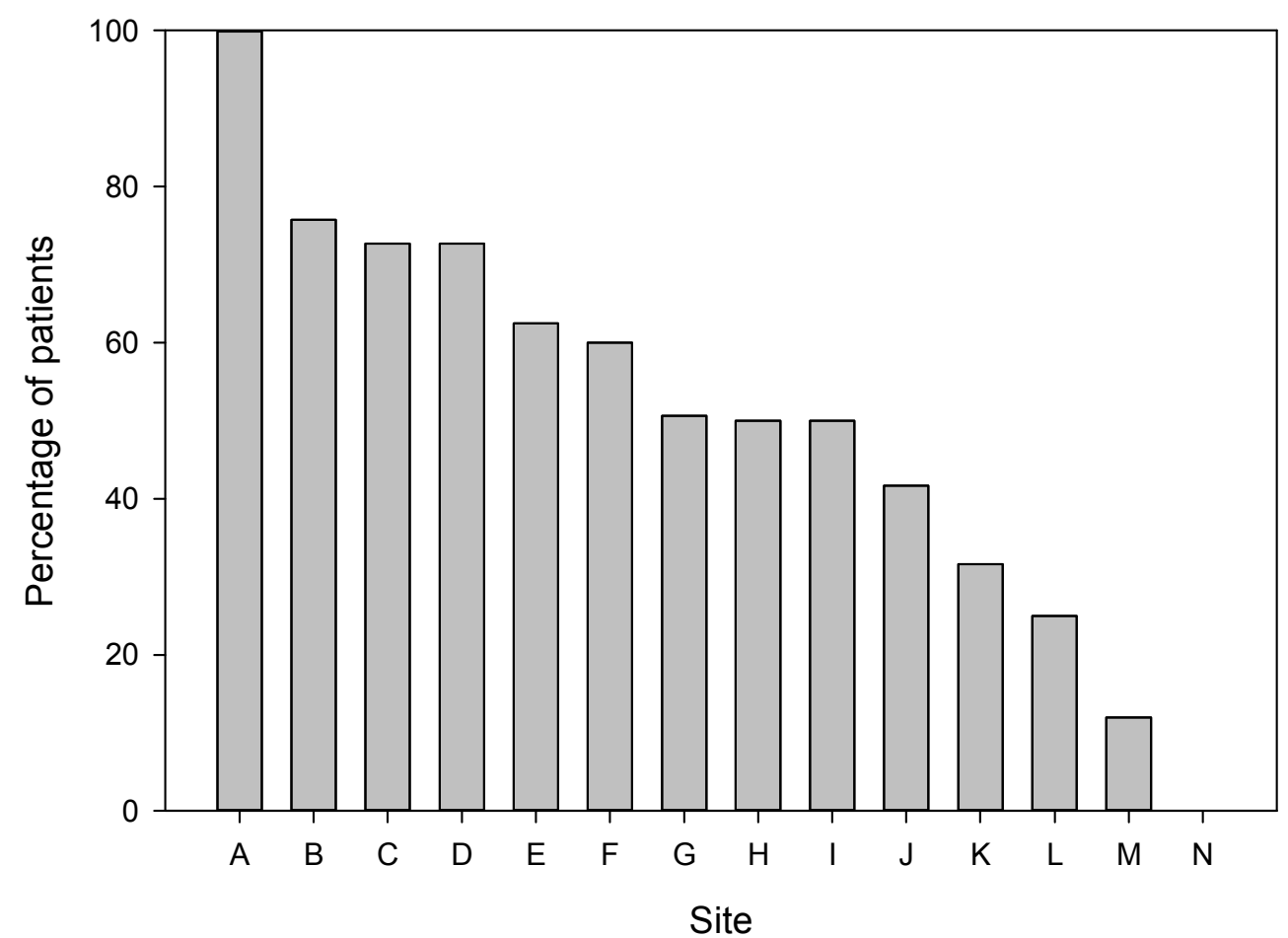

Number of patients

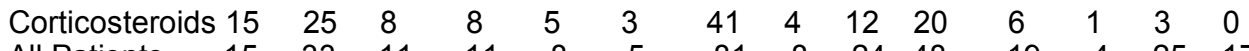

$\begin{array}{lllllllllllllll}\text { All Patients } & 15 & 33 & 11 & 11 & 8 & 5 & 81 & 8 & 24 & 48 & 19 & 4 & 25 & 17\end{array}$


Supplement Figure E2. Physiological parameters in the corticosteroid therapy group and no corticosteroid therapy group. Please note that the varaibles are presented starting on ICU day 1, although corticorstoid therapy may have been started on a different time point as shown in Figure 1 in the main manuscript. * denotes statistical significance for the difference between the two groups on each day after Bonferroni correction using independent Student's t-test or Mann-Whitney U test, as appropriate. $\mathrm{P}$ values for differences with time and for between-group differences over time using repeated measures analysis of variance are given for each variable. A. The ratio of partial pressure of oxygen in arterial blood/ the fraction of inspired oxygen $\left(\mathrm{PaO}_{2} / \mathrm{FiO}_{2}\right)$, B. Tidal volume, C. Positive end expiratory pressure (PEEP), D. Platelet count, E. Creatinine, $\mathbf{F}$. Sequential Organ Failure Assessment (SOFA) score, G. Lactate (mmol/L), H. Bilirubin (mmol/L), I. Blood Urea Nitrogen $(\mathrm{mmol} / \mathrm{L})$, J. pH, K. $\mathrm{PCO}_{2}(\mathrm{mmHg})$, L. Hemoglobin (g/dL), M. Alanine amino transferase (ALT) (U/L)

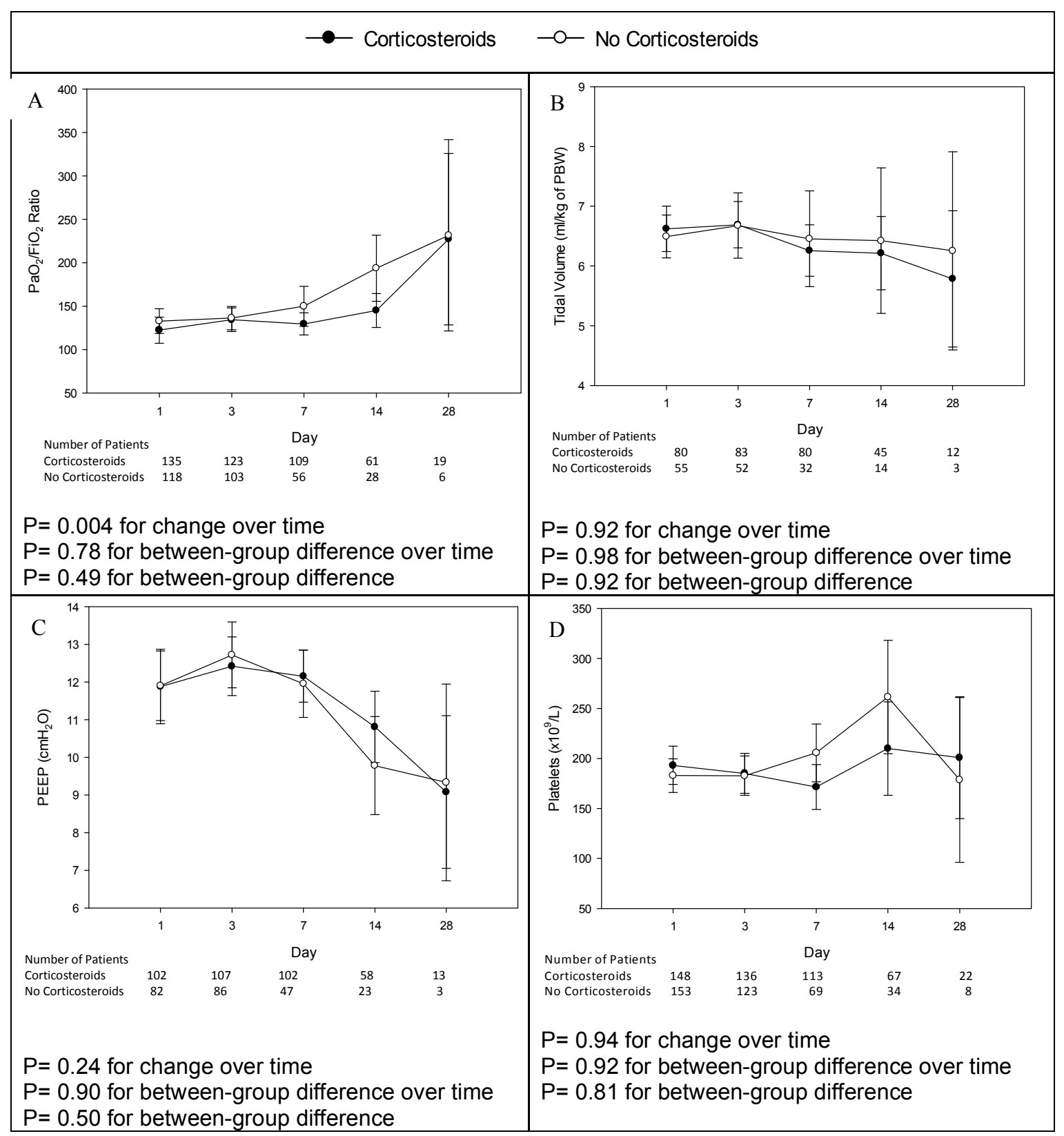




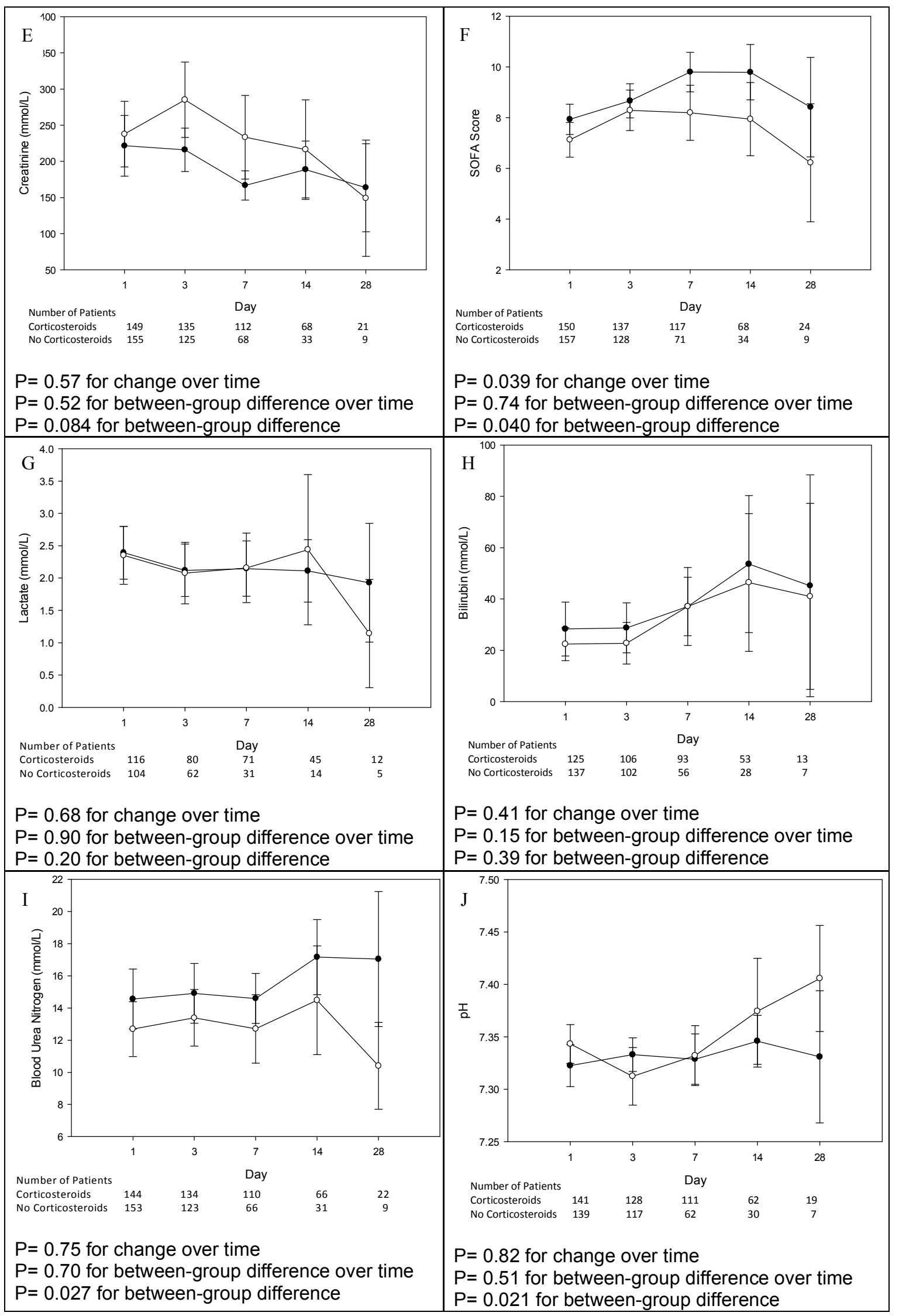




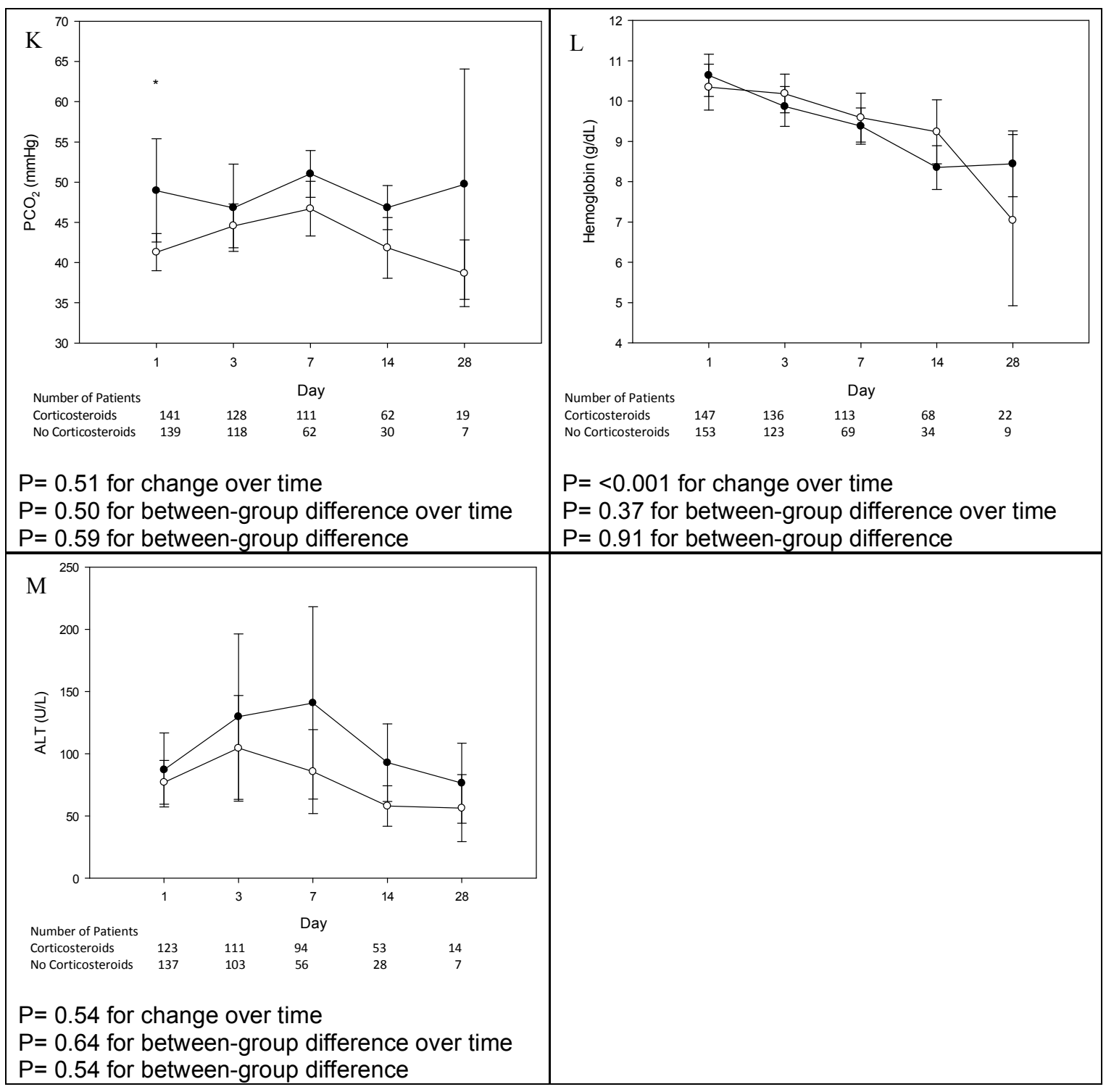

